\title{
Variables determinantes de la transparencia municipal en la gestión de los residuos sólidos urbanos
}

\author{
Alejandro Rodríguez Martín ${ }^{1}$, Ricardo Palomo $\operatorname{Zurdo}^{2}$, Elena Urquía Grande ${ }^{3}$, y Francisco \\ González Sánchez ${ }^{4}$
}

Recibido: 20 de octubre del 2021 / Aceptado: 21 de diciembre del 2021 / Publicado: 14 de enero del 2022.

Resumen. Esta investigación pretende analizar las variables que pueden tener una relación significativa con el nivel de transparencia en la gestión de los residuos municipales, medido a través del Índice de Transparencia Municipal en la Gestión de Residuos, propuesto en el estudio de Rodríguez-Martín et.al. (2020) y aplicado sobre una muestra de 96 ayuntamientos españoles a partir de la información publicada en sus páginas webs y portales de transparencia, relativa al año 2017. Las variables independientes seleccionadas han sido de carácter sociodemográficas, políticas, de gestión y económico-presupuestarias. Los resultados obtenidos a partir del Modelo de Regresión Lineal Multivariante de Mínimos Cuadrados Ordinarios, confirman que los ayuntamientos con mayor nivel de transparencia en la gestión municipal de los residuos sólidos urbanos son aquellos con mayor población, con mayores niveles de renta bruta media, disponen del llamado quinto contenedor y, aunque con menor incidencia, que presentan unos mayores ingresos fiscales. Palabras clave: Residuos municipales; Panel de indicadores; Webs municipales; Índice de Transparencia; Variables independientes; Sostenibilidad.

Claves Econlit: H75; O44; Q53; Z18.

[en] Fundamental factors of local government transparency in the management of urban solid waste

\begin{abstract}
This research aims to analyze the variables that may have a significant relationship in relation to the level of transparency in municipal waste management, measured through the Municipal Transparency Index in Waste Management, proposed in the research carried out by Rodríguez- Martin et.al. (2020), applied to a sample of 96 Spanish city councils examining the information published on their transparency websites, relative to the year 2017 . The independent variables have been chosen, spanning from demographic, political, management and budgetary fields. The results obtained from the Multiple Linear Regression Model, confirm that the municipalities with the highest level of transparency in Municipal Management of Urban Solid Waste are those with the largest population, with the largest levels of average gross income, those that have the so-called fifth container and, although with less incidence, those that show higher tax revenues.

Keywords: Municipal waste; Indicators panel; Municipal websites; Transparency Index; Independent variables; Sustainability.
\end{abstract}

Sumario. 1. Introducción. 2. Contexto histórico. 3. Metodología. 4. Diseño e implementación. 5. Resultados del análisis. 6. Conclusiones. 7. Referencias bibliográficas.

Cómo citar. Rodríguez Martín, A.; Palomo Zurdo, R.; Urquía Grande, E.; González Sánchez, F. (2022). Variables determinantes de la transparencia municipal en la gestión de los residuos sólidos urbanos. REVESCO. Revista de Estudios Cooperativos, vol. 140, e79715. https://dx.doi.org/10.5209/REVE.79715.

\section{Introducción}

El interés por parte de los ciudadanos europeos en el medio ambiente es cada vez mayor, la encuesta del Eurobarómetro publicada en marzo de 2020 refleja que el 94\% de los ciudadanos comunitarios consideran

1 Universidad San Pablo CEU, España.

Dirección de correo electrónico: rodmar@ceu.es.

2 Universidad San Pablo CEU, España.

Dirección de correo electrónico: palzur@ceu.es

3 Universidad Complutense de Madrid, España.

Dirección de correo electrónico: eurquiag@ccee.ucm.es

4 Universidad San Pablo CEU, España.

Dirección de correo electrónico: francisco.gonzalezsanchez@ceu.es 
fundamental la protección del medio ambiente, siendo el cambio climático, la contaminación atmosférica y los residuos los tres problemas más importantes, considerando el $78 \%$ de los encuestados que los mismos tienen un efecto directo en su vida diaria y en su salud.

La importancia de implementar políticas de prevención en la generación y tratamiento de residuos para hacer compatibles el desarrollo económico y la protección del medio ambiente, quedan reflejadas en múltiples estudios. Así, por ejemplo, Naciones Unidas publica en el año 2017 un informe en el que se afirma con rotundidad que las botellas de plástico representan un componente importante de la basura marina, estimando que anualmente se filtran en nuestros océanos ocho millones de toneladas de plástico, su principal componente, además de los 1.300 millones de toneladas anuales de alimentos que se tiran o se desperdician, según la Organización de Naciones Unidas para la Alimentación y la Agricultura (FAO). Por otro lado, en el año 2018 el departamento de Asuntos Económicos y Sociales de Naciones Unidas estima que el 70\% de la población del planeta vivirá en ciudades en el año 2050, y habrá entre 6.000 y 7.000 millones de consumidores de clase media en todo el mundo que ejercerán una mayor presión sobre el consumo y el medio ambiente.

Como consecuencia de todo ello, el Banco Mundial prevé un incremento del 70\% en la generación mundial de los residuos sólidos urbanos (RSU), pasando de los 1.300 millones de toneladas anuales en el año 2010, a los 2.200 millones para el año 2025, produciéndose el mayor aumento en las ciudades con rápido crecimiento de los países en desarrollo. Dicho incremento se pone de manifiesto en la Asamblea de las Naciones Unidas sobre el Medio Ambiente (2017), donde se estima que anualmente se generan 40 millones de toneladas de desechos electrónicos, cifra que aumenta cada año entre un 4 y un 5\%. Sin olvidar tal como afirma la Agencia de Protección Ambiental de Estados Unidos, que aproximadamente el $42 \%$ de las emisiones totales de gases de efectos invernadero (GEI) está asociado a la gestión de residuos, contribuyendo de forma directa al cambio climático vía la emisión de gases como el dióxido de carbono y el metano.

Todos estos informes ponen de manifiesto que nuestro ecosistema está seriamente amenazado por la actual manera de producir y consumir, basada también en el concepto erróneo de que nuestro planeta es capaz de asimilar todos los vertidos y los residuos que se liberan al medio ambiente.

Por otra parte, la gestión RSU por parte de las corporaciones locales suscita un claro interés y preocupación en la ciudadanía, no solo por sus posibles efectos nocivos en el medio ambiente y el desarrollo sostenible, sino también, por el hecho de que los ciudadanos exigen a la clase política una gestión transparente y eficaz de los servicios públicos, entre ellos la recogida y tratamiento de los RSU. Por ello, el estudio de Rodríguez-Martín et.al. $(2020)^{5}$, pretende verificar si los ciudadanos pueden valorar la transparencia municipal en la gestión de los residuos municipales, para lo cual, en primer lugar, se elaboró el Índice de Transparencia Municipal en la Gestión de Residuos (ITMGR), compuesto por 64 indicadores distribuidos en 7 áreas (a todos los ítems se les asigna la misma ponderación), en segundo lugar, comprobar su grado de cumplimiento por parte de los 96 ayuntamientos de mayor población (incluidas todas las capitales de provincia, Ceuta y Melilla y que representan el $44 \%$ de la población española) a partir de la información publicada en las páginas webs y portales de transparencia municipales, y por último elaborar un ranking con las ponderaciones obtenidas. 
Figura. 1. Indicadores por áreas del ITMGR.

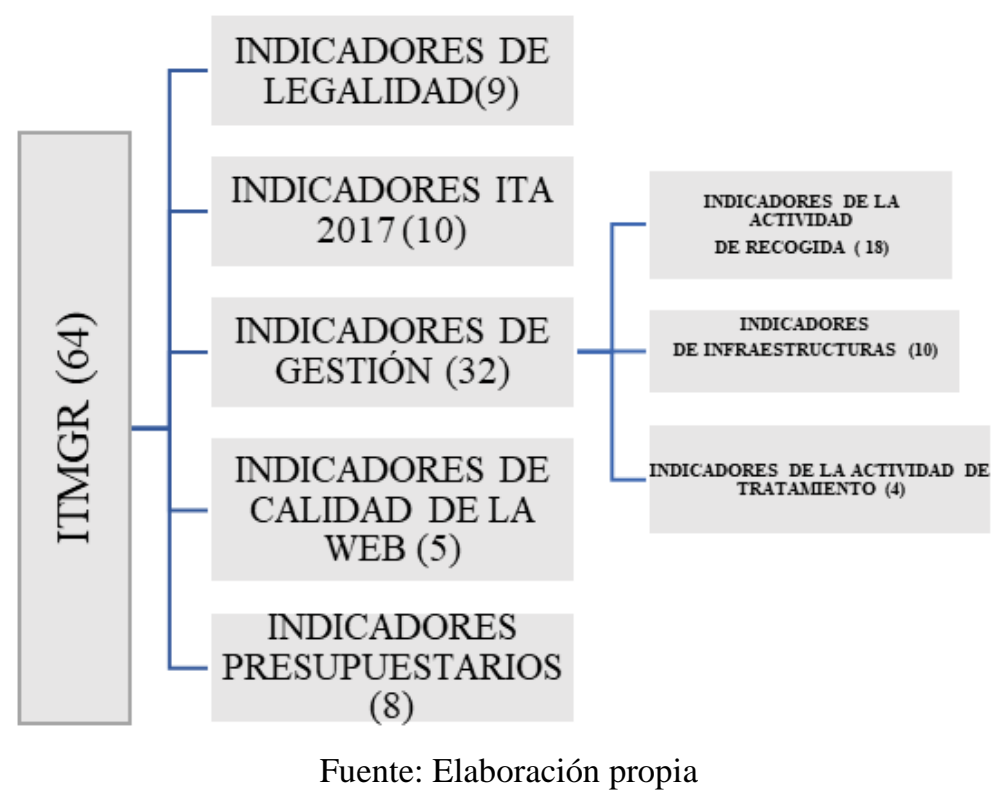

Los resultados de dicha investigación indican unos niveles de transparencia muy discretos, tal como se pueden apreciar a continuación.

Figura. 2. Principales conclusiones de los datos obtenidos a partir del ITMGR.

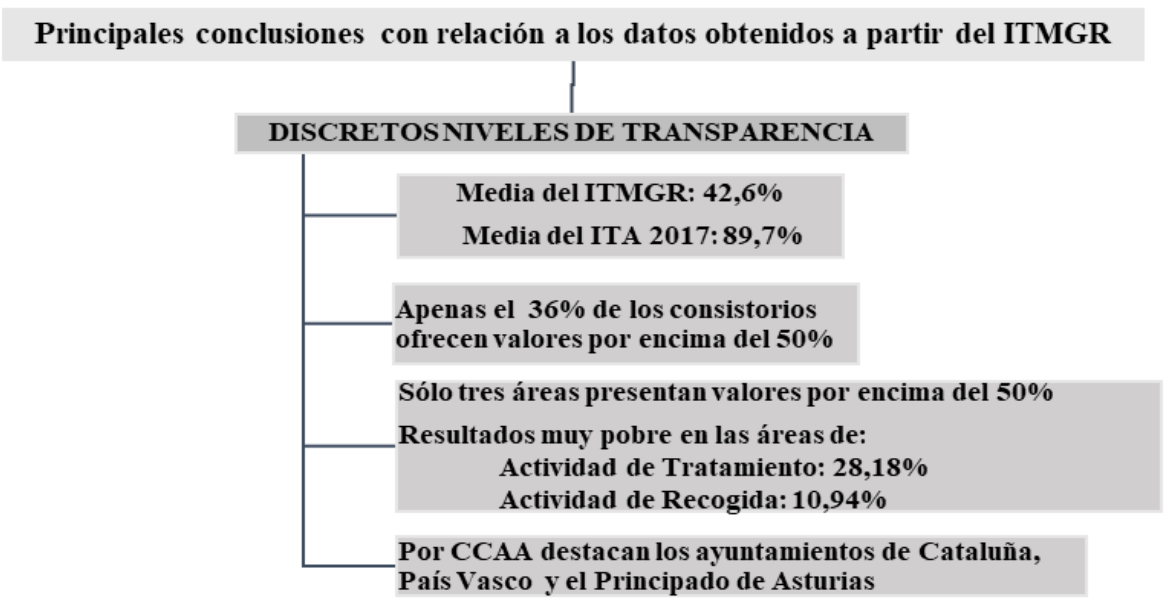

Fuente: Elaboración propia

A partir de dichas conclusiones, en el presente estudio pretendemos determinar la posible influencia de una serie de variables sociodemográficas, políticas y económicas en los niveles de transparencia obtenidos a partir del ITMGR.

Entendemos que la transparencia en la gestión pública resulta particularmente importante en los gobiernos locales porque estos representan el primer nivel de participación de la ciudadanía en los asuntos públicos. Los ciudadanos exigen a la clase política una gestión transparente de los servicios públicos, entre ellos la recogida y tratamiento de los RSU, dado que, por un lado, conlleva el pago de las correspondientes tasas municipales, y, por otro lado, tal como se ha comentado anteriormente, el interés y la preocupación por el medio ambiente es cada vez mayor.

La gestión y tratamiento de los residuos tiene una incidencia clara en lograr un crecimiento sostenible y también en otras políticas ambientales, en concreto en la lucha contra el cambio climático, la protección de las aguas continentales, los ecosistemas y la biodiversidad, y por supuesto en la salud humana. 
Por último, aunque existe una amplia bibliografía que recoge numerosos estudios sobre el nivel de transparencia municipal en España, escasa es la investigación sobre la evaluación del nivel de transparencia municipal en el área de medio ambiente, y más en concreto en la recogida, tratamiento y eliminación de los RSU, así como la influencia que pueden ejercer una serie de variables socio-demográficas, políticas o económicas sobre dichos niveles de transparencia, siendo por tanto este el principal objetivo del presente estudio.

Figura. 3. Justificación de la investigación

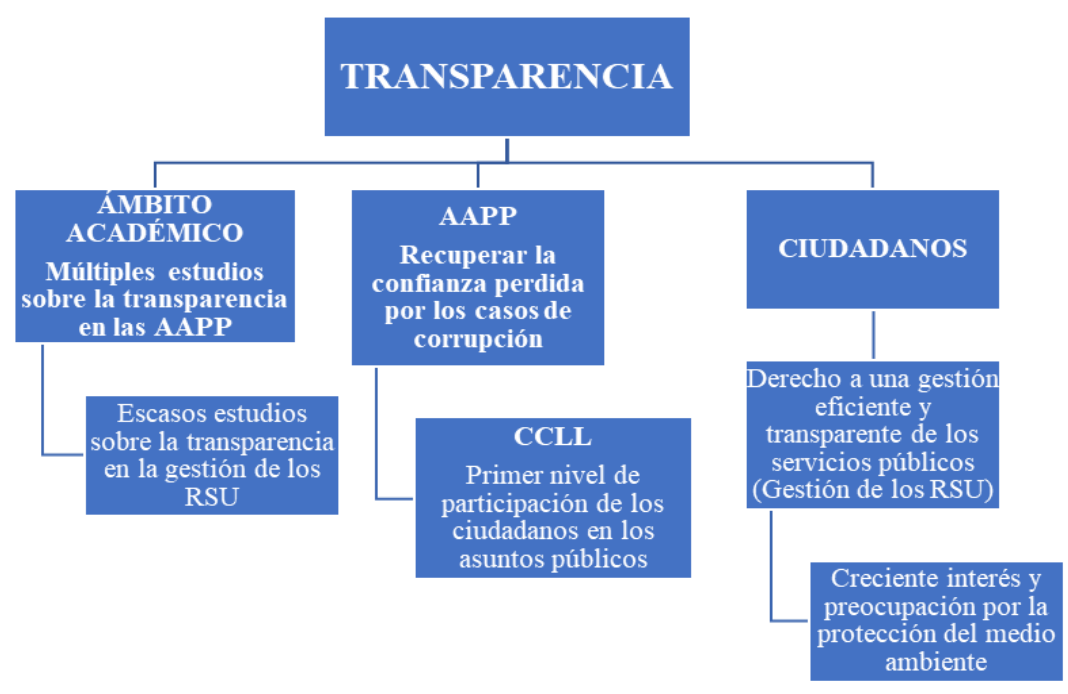

Fuente: Elaboración propia

\section{Contexto histórico}

La preocupación de los organismos internacionales por el medio ambiente no se manifiesta explícitamente hasta la década de los 70, en concreto con la Conferencia de Naciones Unidas sobre el Medio Humano (1972), y que da lugar al Programa de las Naciones Unidas para el Medio Ambiente.

Dos décadas después, en la Conferencia de las Naciones Unidas sobre el Medio Ambiente y el Desarrollo (1992), se reconoció internacionalmente el hecho de que los problemas medio ambientales del planeta están íntimamente relacionados con las condiciones socioeconómicas y los problemas de la justicia social, y que por tanto las necesidades sociales, medio ambientales y económicas deben equilibrarse unas a otras para obtener resultados sostenibles a largo plazo. El resultado de la Cumbre fue la aprobación del denominado Programa o Agenda 21, plan de acción exhaustivo que pretende ser adoptado a nivel universal, nacional y local por los gobiernos y las Administraciones Públicas (AAPP) que lo ratificaron, y que se basa en una serie de principios de desarrollo sostenible en pro de una mejora ambiental continua. Dicho documento dedica un capítulo completo a la gestión racional de los residuos sólidos urbanos, a través de cuatro programas de acción relativos a reducir la generación de los residuos, incrementar la reutilización, el reciclaje y la eliminación y el tratamiento ecológicamente racional de los mismos.

En la Cumbre de las Naciones Unidas sobre el Desarrollo Sostenible (2015), los 193 estados miembros llegaron a un consenso sobre el documento final conocido como Agenda 2030, que cambia el modelo de desarrollo económico, social, cultural y medioambiental. Este documento fija 17 objetivos de desarrollo sostenible a alcanzar en el año 2030, entre ellos el objetivo $11^{\circ}$, "Lograr que las ciudades y los asentamientos humanos sean inclusivos, seguros y sostenibles" y el $12^{\circ}$ "Garantizar modalidades de consumo y producción sostenibles", que están directamente relacionados con la gestión de los residuos municipales.

En el ámbito de la Unión Europea (UE), el origen de la actual economía circular aparece en el año 2010 cuando se pone en marcha la conocida como "Estrategia Europa 2020" que fija cinco objetivos para lograr un crecimiento inteligente, sostenible e integrador hasta el año 2020 a través de siete iniciativas, entre ellas, una Europa que utilice eficazmente los recursos. 
El apoyo de la UE a los principios de la economía circular para garantizar un uso más eficiente y racional de los recursos naturales queda plasmado en la firma del llamado Pacto Verde Europeo ${ }^{6}$, como parte integrante de la estrategia de la Comisión para aplicar la Agenda 2030 y los objetivos de desarrollo sostenible de Naciones Unidas, así como en la promulgación de cuatro nuevas directivas comunitarias en 2018, que establecen entre otras cuestiones, unos objetivos mucho más ambiciosos en materia de preparación para la reutilización y de reciclado de los residuos, tal como se puede apreciar en el siguiente cuadro.

Cuadro. 1. Objetivos de recogida y tratamiento de residuos según la normativa europea.

\begin{tabular}{|c|c|c|}
\hline Norma & Fecha & Objetivo \\
\hline$>$ Directiva (UE) 2018/851 & 2024 & Recogida separada de los biorresiduos. \\
\hline$>$ Directiva (UE) $2018 / 851$ & 2025 & $\begin{array}{l}\text { Recogida separada de las fracciones de residuos peligrosos de origen } \\
\text { doméstico. }\end{array}$ \\
\hline$>$ Directiva (UE) $2018 / 851$ & 2025 & Recogida separada de textiles. \\
\hline$>$ Directiva (UE) 2018/851 & $\begin{array}{l}2025 \\
2030 \\
2035\end{array}$ & $\begin{array}{l}\text { Preparación para la reutilización y el reciclado del } 55 \% \text { en peso de } \\
\text { los residuos municipales generados. } \\
60 \% \text {. } \\
65 \% \text {. }\end{array}$ \\
\hline
\end{tabular}

Fuente: Elaboración propia

La transposición de las nuevas directivas comunitarias al ordenamiento jurídico español da lugar a la modificación de la Ley 22/2011 de Residuos y Suelos Contaminados y el Anteproyecto de Ley de Residuos y Suelos Contaminados ${ }^{7}$, presenta entre otras, las principales novedades recogidas en la siguiente figura.

Figura. 4. Principales novedades del Anteproyecto de Ley de Residuos y Suelos Contaminados.

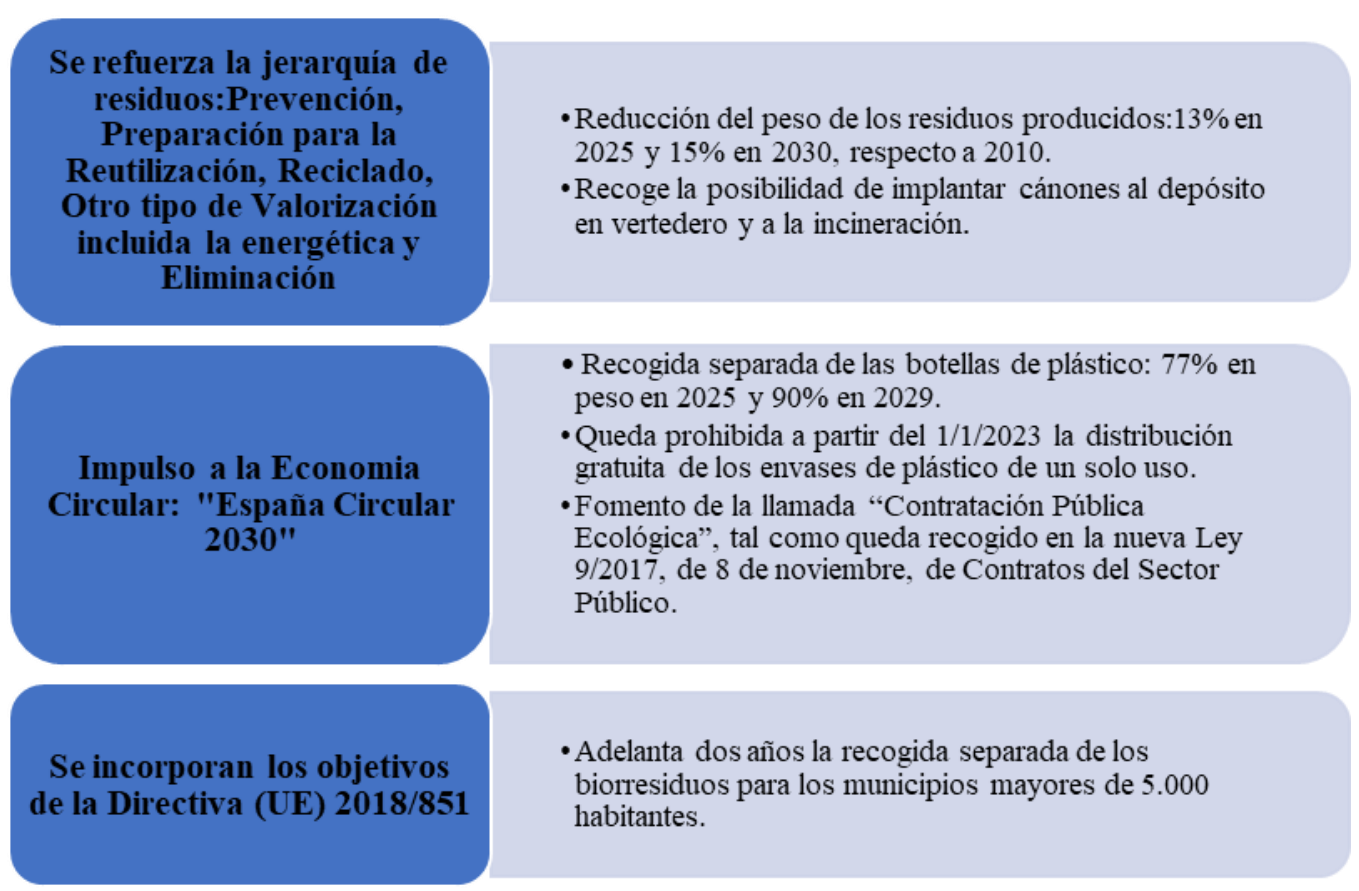

Fuente: Elaboración propia

6 Comunicación de la Comisión al Parlamento Europeo, al Consejo, al Comité Económico y Social Europeo y al Comité de las Regiones. "El Pacto Verde Europeo". COM/2019/640 final. Bruselas 11.12.2019.

https://www.miteco.gob.es/es/calidad-y-evaluacion-ambiental/participacion-

publica/Residuos $\% 202020 \% 20$ anteproyecto $\% 20 \mathrm{de} \% 201 \mathrm{ey} \% 20 \mathrm{de} \% 20$ residuos $\% 20$ y $\% 20$ suelos $\% 20$ contaminados.aspx. 


\section{Metodología}

Se ha realizado un estudio de Regresión Lineal Multivariante, a través de un Modelo de Mínimos Cuadrado Ordinarios, donde la variable dependiente será nuestro índice de transparencia, mientras que las 21 variables independientes relativas al año 2017, quedan agrupadas en cinco apartados, variables socio-demográficas, políticas, de gestión, económicas y presupuestarias, junto con 19 variables dicotómicas de situación geográfica (17 CCAA más las dos ciudades autónomas) tal como se puede apreciar en el siguiente cuadro, así como su medición y fuente.

Cuadro. 2. Variables independientes, acrónimos, medición y fuente.

\begin{tabular}{|c|c|c|c|}
\hline & Variable & Medición & Fuente \\
\hline \multirow{8}{*}{ 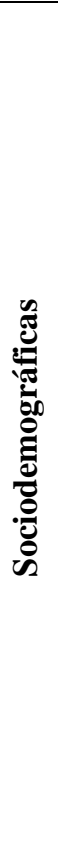 } & Población (POBMIL) & $\mathrm{N}^{\circ}$ de habitantes del municipio & INE \\
\hline & Hab.>65 años (POB65) & $\begin{array}{c}\mathrm{N}^{\mathrm{o}} \text { de habitantes mayores de } 65 \text { años del } \\
\text { municipio }\end{array}$ & INE \\
\hline & Nivel educativo (NIVEDU) & $\begin{array}{c}\mathrm{N}^{\circ} \text { de hab. entre } 25-65 \text { años con título } \\
\text { universitario/ } \mathrm{N}^{\circ} \text { total de hab. }\end{array}$ & INE \\
\hline & $\begin{array}{l}\text { \% de impropios en el } \\
\text { contenedor amarillo } \\
\text { (IMPRO) }\end{array}$ & $\begin{array}{l}\text { Tn. de residuos impropios depositados en el } \\
\text { contenedor amarillo/ Tn. totales de envases }\end{array}$ & Ecoembes \\
\hline & $\begin{array}{l}\text { Capital de provincia } \\
\quad(C A P P R O V)\end{array}$ & $\begin{array}{l}1: \mathrm{Si} \\
0: \mathrm{No}\end{array}$ & INE \\
\hline & $\begin{array}{l}\text { Ayto. Turístico } \\
\text { (AYTOTURMIL) }\end{array}$ & Número de plazas hoteleras disponibles & INE \\
\hline & Ayto. Costero (AYTOCOST) & $\begin{array}{l}1: \mathrm{Si} \\
0 . \mathrm{No}\end{array}$ & INE \\
\hline & $\begin{array}{c}\text { Implantado el } 5^{a} \text { contenedor } \\
\text { de residuos orgánicos } \\
(C O N T)\end{array}$ & $\begin{array}{l}\text { 1: Dispone del } 5^{\circ} \text { contenedor } \\
0: \text { No dispone del } 5^{\circ} \text { contenedor }\end{array}$ & Webs municipales \\
\hline \multirow{2}{*}{ 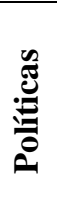 } & $\begin{array}{l}\text { Ideología del gobierno del } \\
\text { consistorio (IDEO) }\end{array}$ & $\begin{array}{l}\text { 1: Derecha } \\
0: \text { Izquierda }\end{array}$ & Webs municipales \\
\hline & $\begin{array}{l}\text { Ideología de la CCAA. } \\
\quad(\text { IDEOCOIN) }\end{array}$ & $\begin{array}{l}\text { 1: Coincide } \\
0: \text { No coincide }\end{array}$ & Webs municipales \\
\hline \multirow{2}{*}{ 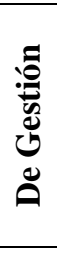 } & $\begin{array}{l}\text { Pública/Privada (GESTION } \\
\text { PUBLICA/PRIVADA) }\end{array}$ & $\begin{array}{l}\text { 1: Recogida de residuos por el propio municipio } \\
\text { 0: Recogida de residuos a través de una empresa } \\
\text { privada }\end{array}$ & Webs municipales \\
\hline & $\begin{array}{c}\text { Individual/Conjunta } \\
\text { (GESTION } \\
\text { INDIVIDUAL/CONJUNTA) } \\
\end{array}$ & $\begin{array}{l}\text { 1: Recogida de residuos de manera individual } \\
\text { 0: Recogida de residuos de manera conjunta }\end{array}$ & Webs municipales \\
\hline \multirow{6}{*}{ 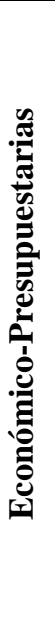 } & Tasa de paro $(\mathrm{PARO})$ & $\mathrm{N}^{\mathrm{o}}$ de desempleados/ Población Activa & INE \\
\hline & $\begin{array}{l}\text { Renta bruta media } \\
\text { (RBMEDMIL) }\end{array}$ & Renta bruta $/ \mathrm{N}^{\circ}$ de declaraciones & AEAT \\
\hline & $\begin{array}{l}\text { Deuda viva/hab. } \\
\text { (DEUHABMIL) }\end{array}$ & Deuda financiera $/ \mathrm{N}^{\circ}$ de hab. & $\mathrm{M}^{\mathrm{o}}$ de Hacienda \\
\hline & $\begin{array}{c}\text { Gasto/hab. } \\
(\text { GASTOHEUROS) }\end{array}$ & $\begin{array}{l}\text { Créditos iniciales del Programa 162: } \\
\text { Recogida, gestión y tratamiento de residuos/ } \\
\mathrm{N}^{\circ} \text { de hab. }\end{array}$ & $\mathrm{M}^{\mathrm{o}}$ de Hacienda \\
\hline & $\begin{array}{l}\text { Gasto del programa } \\
\text { (162)/Pto. de gastos } \\
\text { (PTOGASTOS) } \\
\end{array}$ & $\begin{array}{l}\text { Créditos iniciales del programa 162/ Presupuesto } \\
\text { total del ayuntamiento (créditos iniciales) }\end{array}$ & $\mathrm{M}^{\mathrm{o}}$ de Hacienda \\
\hline & $\begin{array}{c}\text { Tasa de basura } \\
(\text { TASBASURA) }\end{array}$ & $\begin{array}{l}\text { 1: Si tiene implantada una tasa de basuras } \\
\text { 0: No tiene implantada una tasa de basuras }\end{array}$ & Webs municipales \\
\hline
\end{tabular}




\begin{tabular}{|c|c|c|c|}
\hline & $\begin{array}{c}\text { Inversión/hab. } \\
\text { (INVERHABEUROS) }\end{array}$ & 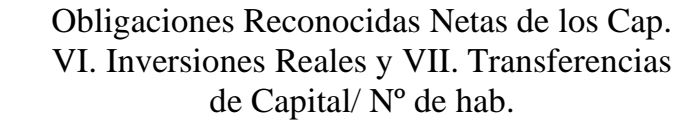 & $\mathbf{M}^{\mathbf{o}}$ de Hacienda \\
\hline & $\begin{array}{c}\text { Autonomía Financiera } \\
\text { (AUTONFINAN) }\end{array}$ & $\begin{array}{c}\text { El total de DRN menos las Transferencias } \\
\text { Corrientes (Cap. IV) y de Capital (Cap.VII) } \\
\text { recibidas/Total de derechos reconocidos netos } \\
\text { (DRN) }\end{array}$ & $\mathrm{M}^{\mathrm{o}}$ de Hacienda \\
\hline & $\begin{array}{c}\text { Ingresos fiscales/hab. } \\
\text { (INGFISMIL) }\end{array}$ & Ingresos de naturaleza fiscal $/ \mathrm{N}^{\circ}$ de hab. & $\mathbf{M}^{\mathbf{o}}$ de Hacienda \\
\hline 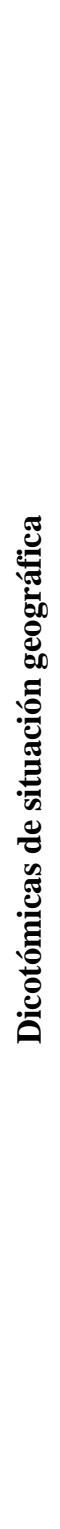 & $\begin{array}{c}\text { Andalucía } \\
\text { (DDUMMYCCAA 0) } \\
\text { Aragón } \\
\text { (DDUMMYCCAA 1) } \\
\text { P. de Asturias } \\
\text { (DDUMMYCCAA 2) } \\
\text { I. Baleares } \\
\text { (DDUMMYCCAA 3) } \\
\text { I. Canarias } \\
\text { (DDUMMYCCAA 4) } \\
\text { Cantabria } \\
\text { (DDUMMYCCAA 5) } \\
\text { Castilla y León } \\
\text { (DDUMMYCCAA 6) } \\
\text { Castilla-La Mancha } \\
\text { (DDUMMYCCAA 7) } \\
\text { Cataluña } \\
\text { (DDUMMYCCAA 8) } \\
\text { Extremadura } \\
\text { (DDUMMYCCAA 9) } \\
\text { Galicia } \\
\text { (DDUMMYCCAA 10) } \\
\text { Madrid } \\
\text { (DDUMMYCCAA 11) } \\
\text { R. de Murcia } \\
\text { (DDUMMYCCAA 12) } \\
\text { Navarra } \\
\text { (DDUMMYCCAA 13) } \\
\text { País Vasco } \\
\text { (DDUMMYCCAA 14) } \\
\text { La Rioja } \\
\text { (DDUMMYCCAA 15) } \\
\text { C. Valenciana } \\
\text { (DDUMMYCCAA 16) } \\
\text { Ceuta } \\
\text { MDElilla } \\
\text { (DDUMMYCAA 18) }\end{array}$ & & \\
\hline
\end{tabular}

Fuente: Elaboración propia

Para la elección de las anteriores variables nos hemos basado en los estudios previos sobre transparencia municipal, publicados en España hasta el año 2019, tanto aquellos basados en el ITA (Índice de Transparencia de los Ayuntamientos, publicado por Transparencia Internacional España) como otros no basados en el ITA. 
Cuadro. 3. Análisis de las investigaciones sobre transparencia en los ayuntamientos españoles.

\begin{tabular}{|c|c|c|c|c|}
\hline \multicolumn{5}{|l|}{ Estudios no basados en el ITA } \\
\hline Autores & $\begin{array}{l}\text { Muestra } \\
\text { seleccionada }\end{array}$ & $\begin{array}{l}\text { Índice de } \\
\text { Transparencia }\end{array}$ & $\begin{array}{l}\text { Variables } \\
\text { relacionadas con } \\
\text { mayores niveles } \\
\text { de transparencia }\end{array}$ & $\begin{array}{l}\text { Variables no } \\
\text { relacionadas con } \\
\text { mayores niveles } \\
\text { de transparencia }\end{array}$ \\
\hline Serrano et al. (2008) & 92 municipios & $\begin{array}{l}\text { Índice de } \\
\text { publicación de } \\
\text { información } \\
\text { financiera }\end{array}$ & $\begin{array}{l}\text { Tamaño por } \\
\text { población } \mathbf{v . 1} \\
>\text { Nivel de } \\
\text { rentav.12 } \\
>\text { Nivel educativo } \\
\text { v.3 }\end{array}$ & \\
\hline Cárcaba y García (2008) & $\begin{array}{l}334 \text { municipios> } \\
20.000 \text { hab. }\end{array}$ & $\begin{array}{l}\text { Índice de } \\
\text { divulgación de } \\
\text { información } \\
\text { financiera }\end{array}$ & $\begin{array}{l}>\text { Tamaño por } \\
\text { poblaciónv.1 } \\
>\text { Inversión v.16 } \\
>\text { Competencia } \\
\text { política v.9 } \\
>\text { Bajo grado de } \\
\text { notoriedad del } \\
\text { municipio v.6 }\end{array}$ & $\begin{array}{l}>\text { Endeudamiento } \\
\text { v.13 }\end{array}$ \\
\hline Fernández et al. (2011) & $\begin{array}{l}211 \text { municipios de } \\
\text { León }\end{array}$ & $\begin{array}{l}\text { Índice de } \\
\text { valoración de } \\
\text { las webs } \\
\text { municipales }\end{array}$ & & \\
\hline $\begin{array}{l}\text { Esteller-Moré y Polo Otero } \\
(2012)\end{array}$ & $\begin{array}{l}691 \text { municipios } \\
\text { catalanes }\end{array}$ & $\begin{array}{l}\text { Índice de } \\
\text { transparencia } \\
\text { fiscal }\end{array}$ & $\begin{array}{l}\text { Competencia } \\
\text { política v.9 } \\
>\text { Población > } 65 \\
\text { años v.2 } \\
>\text { Menor tamaño } \\
\text { del municipio v.1 }\end{array}$ & $\begin{array}{l}\text { Déficit v.14 } \\
\text { Transferencias } \\
\text { recibidas v.17 } \\
\text { \% Abstención } \\
\mathbf{v . 1 0} \\
>\text { Ideología } \\
\text { política v.8 }\end{array}$ \\
\hline Caamaño-Alegre et al.(2013) & $\begin{array}{l}33 \text { municipios } \\
\text { gallegos }\end{array}$ & $\begin{array}{l}\text { Índice de } \\
\text { transparencia } \\
\text { fiscal, basado en } \\
\text { el del FMI de } \\
2007\end{array}$ & $\begin{array}{l}>\text { Ideología } \\
\text { progresista v.8 } \\
>\text { Tasa de paro } \\
(-) \mathbf{v . 1 5} \\
>\text { Competencia } \\
\text { política (-) v.9 } \\
>\text { Gasto público } \\
\text { (-) v.16 }\end{array}$ & \\
\hline Vila-i-Vila (2013) & $\begin{array}{l}529 \text { municipios } \\
\text { valencianos }\end{array}$ & $\begin{array}{l}\text { Índice de } \\
\text { transparencia } \\
\text { financiera }\end{array}$ & $\begin{array}{l}>\text { Tamaño v.1 } \\
>\text { Inversión per } \\
\text { cápita v.16 } \\
>\text { Deuda per cápita } \\
(-) \mathbf{v . 1 3} \\
>\text { Competencia } \\
\text { política (-) v.9 }\end{array}$ & $\begin{array}{l}>\text { \%Abstención } \\
\mathbf{v . 1 0} \\
>\text { Ideología } \\
\text { política v.8 }\end{array}$ \\
\hline Alcaraz-Quiles (2014) & $\begin{array}{l}55 \text { mayores } \\
\text { ayuntamientos }\end{array}$ & $\begin{array}{l}\text { Índice de } \\
\text { divulgación de } \\
\text { las memorias de } \\
\text { sostenibilidad }\end{array}$ & $\begin{array}{l}>\text { Población > 65 } \\
\text { años v.2 } \\
>\text { Presión fiscal } \\
\quad(-) \text { v.18 } \\
>\text { Autonomía } \\
\text { financiera v.17 }\end{array}$ & $\begin{aligned} & \text { Endeudamiento } \\
& \mathbf{v . 1 3} \\
> & \text { Competencia } \\
& \text { política v.9 } \\
> & \text { Ideología v.8 }\end{aligned}$ \\
\hline Frías-Aceituno et.al (2014) & 102 municipios & $\begin{array}{l}\text { Índice de } \\
\text { Gobierno } \\
\text { Electrónico (75 } \\
\text { items) }\end{array}$ & $\begin{array}{l}\text { Tamaño v.1 } \\
>\text { Ideología } \\
\text { conservadora } \\
(-) \mathbf{v} .8\end{array}$ & $\begin{array}{ll} & \text { Tasa de } \\
& \text { empleo v.15 } \\
> & \text { Competencia } \\
& \text { política v.9 } \\
> & \text { Renta per } \\
\text { cápita v.12 }\end{array}$ \\
\hline
\end{tabular}




\begin{tabular}{|c|c|c|c|c|}
\hline $\begin{array}{l}\text { Nevado-Gil y Gallardo-Vázquez } \\
\text { (2016) }\end{array}$ & 58 municipios & $\begin{array}{l}\text { Índice de } \\
\text { divulgación en } \\
\text { materia de } \\
\text { responsabilidad } \\
\text { social (RS) }\end{array}$ & $\begin{array}{l}>\text { Tamaño v.1 } \\
>\text { Población > } 65 \\
\text { años v.2 } \\
>\text { Nivel educativo } \\
\mathbf{v . 3} \\
>\text { Participación } \\
\text { electoral v.10 }\end{array}$ & \\
\hline Navarro et.al (2016) & $\begin{array}{l}144 \text { municipios > } \\
50.000 \text { hab. }\end{array}$ & $\begin{array}{l}\text { Índice de } \\
\text { Transparencia } \\
\text { propio (10 } \\
\text { ítems) }\end{array}$ & $\begin{array}{l}\text { Damaño v.1 } \\
\text { > Inversión per } \\
\text { cápita v.16 } \\
>\text { Nivel educativo } \\
\mathbf{v . 3}\end{array}$ & \\
\hline \multicolumn{5}{|l|}{ Estudios basados en el ITA } \\
\hline Autores & $\begin{array}{l}\text { Muestra } \\
\text { seleccionada }\end{array}$ & $\begin{array}{l}\text { Índice de } \\
\text { Transparencia }\end{array}$ & $\begin{array}{l}\text { Variables } \\
\text { relacionadas con } \\
\text { mayores niveles } \\
\text { de transparencia }\end{array}$ & $\begin{array}{l}\text { Variables no } \\
\text { relacionadas con } \\
\text { mayores niveles } \\
\text { de transparencia }\end{array}$ \\
\hline Lizcano (2009) & $\begin{array}{l}100 \text { mayores } \\
\text { municipios }\end{array}$ & ITA 2008. & & \\
\hline Guillamón et.al (2011) & $\begin{array}{l}100 \text { mayores } \\
\text { municipios }\end{array}$ & $\begin{array}{l}\text { Índice de } \\
\text { transparencia } \\
\text { financiera }\end{array}$ & $\begin{array}{l}\text { > Ideología } \\
\text { progresista v.8 } \\
>\text { Tasa de empleo } \\
\text { v.15 } \\
\text { > Competencia } \\
\text { política v.9 } \\
>\text { Gasto per cápita } \\
\text { v.16 }\end{array}$ & \\
\hline Martín y García (2011) & $\begin{array}{l}110 \text { mayores } \\
\text { municipios }\end{array}$ & ITA 2010 & $\begin{array}{l}>\text { Tamaño v.1 } \\
>\text { Gobiernos en } \\
\text { mayoría (-) v.9 } \\
>\text { Estabilidad } \\
\text { política v.11 } \\
\end{array}$ & $>$ Ideología v.8 \\
\hline Albalate (2013) & $\begin{array}{l}110 \text { mayores } \\
\text { municipios }\end{array}$ & ITA 2010 & $\begin{array}{l}\text { Tamaño por } \\
\text { población v.1 } \\
>\text { Ideología } \\
\text { progresista v.8 } \\
>\text { Actividad } \\
\text { turística (-) v.4 } \\
>\text { Capitales de } \\
\text { provincia (-) v.7 }\end{array}$ & $\begin{array}{l}>\text { Déficit v.14 } \\
>\text { Endeudamiento } \\
\mathbf{v . 1 3}\end{array}$ \\
\hline Alonso y García-García (2014) & $\begin{array}{l}78 \text { municipios } \\
\text { asturianos }\end{array}$ & ITAPA & $\begin{array}{l}\text { Población del } \\
\text { municipio v.1 }\end{array}$ & \\
\hline $\begin{array}{l}\text { Tejedo-Romero y Ferraz Esteves- } \\
\text { Araujo (2015) }\end{array}$ & $\begin{array}{l}100 \text { mayores } \\
\text { municipios }\end{array}$ & ITA & $\begin{array}{l}>\text { Tamaño v.1 } \\
>\text { Tasa de paro } \\
(-) \mathbf{v . 1 5} \\
>\text { Ideología } \\
\text { progresista v.8 } \\
>\text { Competencia } \\
\text { política v.9 }\end{array}$ & $\begin{array}{l}\text { Superávit v.14 } \\
>\text { Presión fiscal } \\
\text { v.18 } \\
>\text { Inversiones } \\
\text { v.16 }\end{array}$ \\
\hline Cañizares (2015) & 38 ayuntamientos & $\begin{array}{l}\text { TAYSS } \\
\text { (Indicador sobre } \\
\text { los servicios } \\
\text { sociales) }\end{array}$ & $\begin{array}{l}>\text { Población> 65 } \\
\text { años v.2 } \\
>\text { Deuda (-) v.13 } \\
>\text { Tamaño (-) v.1 }\end{array}$ & \\
\hline
\end{tabular}




\begin{tabular}{|c|c|c|c|c|}
\hline García et.al (2016) & $\begin{array}{l}75 \text { municipios } \\
\text { asturianos }\end{array}$ & ITA e ITAPA & $\begin{array}{l}\text { Deuda viva v.13 } \\
\text { (aunque disminuye } \\
\text { al aumentar el } \\
\text { tamaño del } \\
\text { municipio) } \\
>\text { Municipios } \\
\text { costeros v.5 } \\
\text { Saldos } \\
\text { pendientes de } \\
\text { aplicar al } \\
\text { presupuesto v.14 }\end{array}$ & $\begin{array}{l}>\text { Ideología } \\
\text { progresista v.8 } \\
>\text { Competencia } \\
\text { política } \mathbf{v . 9}\end{array}$ \\
\hline $\begin{array}{l}\text { Tejedo-Romero y Ferraz Esteves- } \\
\text { Araujo (2018) }\end{array}$ & $\begin{array}{l}110 \text { mayores } \\
\text { municipios }\end{array}$ & ITA 2017 & $\begin{array}{l}\text { Tamaño v.1 } \\
\text { Número de } \\
\text { personas con } \\
\text { acceso a Internet } \\
\text { v.12 } \\
\text { Ideología } \\
\text { progresistav.8 }\end{array}$ & \\
\hline
\end{tabular}

* (-) Relación negativa

Fuente: Elaboración Propia

Las conclusiones fundamentales que se pueden apreciar de los distintos trabajos publicados sobre la transparencia municipal en España son:

1. Los estudios que no se basan en el ITA, elaboran sus propios índices de transparencia como un índice de divulgación financiera: Serrano et.al. (2008); Cárcaba y García (2008) y Vila-i-Vila (2013), un índice de transparencia fiscal: Esteller-Moré y Polo Otero (2012) y Caamaño-Alegre et al. (2013), un índice de divulgación en materia de Responsabilidad Social: Nevado-Gil y Gallardo-Vázquez (2016) y Alcaraz-Quiles (2014), un índice de gobierno electrónico: Frías-Aceituno et al. (2014), un índice basado en el cumplimiento de la Ley 19/2013 (LTAIBG): Navarro et al., y por último un índice sobre la transparencia en servicios sociales (TAYSS): Cañizares (2015).

2. Las principales variables utilizadas en relación a los niveles de transparencia, agrupadas en tres categorías, sociodemográfica (V1-V7), política (V8-V11) y económica(V12-V17) son:

Cuadro. 4. Variables empleadas en las investigaciones sobre la transparencia de los ayuntamientos españoles.

\begin{tabular}{|c|c|c|c|}
\hline Variable & Definición de la variable & Variable & Definición de la variable \\
\hline v.1 & Tamaño del municipio & v.10 & $\begin{array}{l}\text { Porcentaje de participación } \\
\text { en las elecciones municipales }\end{array}$ \\
\hline v. 2 & Población > 65 años & v.11 & Estabilidad política \\
\hline v.3 & Nivel educativo & v.12 & $\begin{array}{l}\text { Renta per cápita/Porcentaje de } \\
\text { vecinos con acceso a Internet }\end{array}$ \\
\hline v.4 & Municipio turístico & v.13 & Endeudamiento \\
\hline v.5 & Municipio costero & v.14 & Resultado presupuestario \\
\hline v.6 & Notoriedad del municipio & v.15 & Tasa de paro \\
\hline v.7 & Capital de provincia & v.16 & Gasto o Inversión per cápita \\
\hline v.8 & Ideología política & v.17 & Transferencias recibidas \\
\hline v.9 & Competencia política & v.18 & Presión fiscal \\
\hline
\end{tabular}

Fuente: Elaboración Propia 
3. En relación a las variables sociodemográficas, el tamaño del municipio por número de habitantes (v.1) así como la población dependiente, mayores de 65 años (v.2), son las que presentan una mayor correlación en relación a los niveles de transparencia.

4. Las variables de carácter político, con excepción tal vez, de la ideología progresista del gobierno municipal, v.8 (hay estudios como Vila-i-Vila 2013, Esteller-Moré y Polo-Otero. 2012, Alcaraz-Quiles 2014 y García et al. 2016, que no la consideran asociada a mayores niveles de transparencia), no tienen una clara influencia en una mayor transparencia municipal.

5. Por último, en cuanto a las variables de carácter económico, los consistorios con menores niveles de desempleo (v.15) y mayor gasto o inversiones (v.16, Capítulos VI. Inversiones reales y VII. Transferencias de capital, del presupuesto municipal), son los que presentan mayores niveles de transparencia.

\section{Diseño e implementación}

Una vez analizados los estudios publicados sobre la transparencia municipal en España, pasamos a definir las siguientes siete hipótesis con relación a las variables independientes seleccionadas anteriormente.

En primer lugar, consideramos que los ayuntamientos más grandes no solo son aquellos que tienen un mayor número de habitantes, sino también los que ocupan una mayor superficie, siendo ambas circunstancias un factor clave en la generación, recogida, transporte y tratamiento de los residuos municipales, junto con el impacto ambiental que conlleva, por tanto, planteamos la siguiente hipótesis:

1. $\mathrm{H}_{1}$ : Existe una relación positiva entre el tamaño poblacional de los ayuntamientos y el nivel de transparencia en la gestión de los residuos municipales.

Dado que nuestro estudio pretende analizar el nivel de transparencia en un área muy concreta como es la gestión de los residuos municipales, hemos considerado que el porcentaje de impropios depositados en el contenedor de envases puede estar relacionada con el nivel de transparencia, en el sentido de que aquellos ayuntamientos que recojan en sus páginas webs campañas de concienciación sobre la importancia del reciclaje, el impacto negativo sobre el medio ambiente al que conducen una malas prácticas de no separación de los residuos domésticos, o la tipología de residuos que se deben depositar en cada contenedor de residuos, puede incidir en un menor porcentaje de residuos depositados de manera incorrecta, en este caso en el contenedor amarillo, dado que es del que se dispone de información. Todo ello nos lleva a plantear nuestra segunda hipótesis:

2. $\mathrm{H}_{2}$ : Existe una relación negativa entre, el porcentaje de impropios depositados en el contenedor de envases y el nivel de transparencia en la gestión de los residuos municipales.

Entendemos que, aunque la obligación para la recogida obligatoria y diferenciada de los biorresiduos queda fijada para antes del 31 de diciembre de 2023, según la Directiva (UE) 2018/851, en el estudio que hemos realizado, 31 de los 96 ayuntamientos seleccionados lo tenían implantado de manera total o parcial antes del 31 de diciembre de 2017. Este hecho nos conduce a pensar que dichos ayuntamientos están más concienciados y comprometidos con una eficiente gestión en la recogida de residuos urbanos, y en concreto de los residuos orgánicos que según numerosos estudios se estiman en torno al $40 \%$ de la fracción resto, y de esta manera, reducir la cuantía de residuos depositados en vertederos y por ende su impacto nocivo en el medio ambiente. Siguiendo con el razonamiento, los responsables municipales de estos ayuntamientos estarían más predispuestos a hacer públicas en sus páginas webs este tipo de políticas para, por un lado, concienciar a sus vecinos e incluso motivarles a través de bonificaciones en la tasa municipal de recogida de basuras, y, por otro lado, para transmitir una eficaz gestión comprometida con el medio ambiente y la Economía Circular. Por todo ello, planteamos la siguiente hipótesis:

3. $\mathrm{H}_{3}$ : Existe una relación positiva entre los ayuntamientos que tienen implantada una recogida separada de los residuos orgánicos y el nivel de transparencia en la gestión de los residuos municipales.

Con relación al resto de variables de carácter socio-demográficas, a pesar de que algunos estudios sobre la transparencia municipal, como el de Alcaráz-Quiles et al. (2015), sobre la divulgación de información sobre sostenibilidad o el de Cañizares (2015), sobre los servicios sociales, sí encuentran una relación positiva con aquellos ayuntamientos que presentan un mayor porcentaje de población mayor de 65 años, o Albalate 
(2013),que basándose en el ITA 2010, encuentra una relación positiva con aquellos ayuntamientos de más relevancia turística y que además son capitales de provincia, entendemos que en nuestra investigación concreta no van a tener una incidencia significativa en los valores que arroje el ITMGR.

En cuanto a las variables de carácter político, si bien es cierto que algunos estudios detectan mayores niveles de transparencia en ayuntamientos gobernados por partidos políticos de izquierda, véase [Guillamón et.al. (2011), Albalate (2013), Caamaño-Alegre et al. (2013) y Tejedo-Romero y Ferraz Esteves-Araujo (2018)], entendemos que la transparencia es una filosofía de gestión, que no entiende de colores políticos, sino más bien de la actitud de los gestores públicos.

Nos situamos por lo tanto en la línea de otra serie de investigaciones basadas o no en el ITA, [Martín y García (2011), Esteller-Moré y Polo (2012), Vila-i-Vila (2013), Alcaráz-Quiles (2014) o García et al. (2016)], que no consideran la ideología política del partido que gobierna en el consistorio, como un factor determinante en el nivel de transparencia municipal, tanto en municipios de mayor como de menor tamaño.

Con relación a las variables de gestión, desde nuestro punto de vista, creemos que los ayuntamientos que realizan de manera directa la recogida de RSU, estarían en principio más obligados a divulgar la información relativa a dicho servicio municipal, al no poder poner como excusa la ausencia de datos por el hecho de que es la empresa concesionaria la que no se los comunica.

Por todo ello, planteamos la siguiente hipótesis:

4. $\mathrm{H}_{4}$ : Existe una relación positiva entre los ayuntamientos que realizan una gestión directa para la recogida de los RSU y el nivel de transparencia en la gestión de los residuos municipales.

Con relación a la gestión de los RSU de manera conjunta o individual, de la muestra de ayuntamientos seleccionados, únicamente 22 ayuntamientos la realizan de manera conjunta, por el contrario, la gran mayoría realizan una gestión individual. Dentro de la gestión conjunta, 11 ayuntamientos se agrupan bajo la fórmula del consorcio, 6 en mancomunidades, y el resto utilizan otras agrupaciones municipios como son la comarca y el área metropolitana.

Independientemente del posible ahorro de costes y de tiempo que puede conllevar una gestión conjunta en la recogida y tratamiento de los RSU, especialmente para ayuntamientos de menor tamaño, la sensación que nos queda una vez realizada la fase de recopilación de datos es que la facilidad y la rapidez en la obtención de información en ayuntamientos que optan por una fórmula conjunta ha sido mayor que en aquellos que realizan una gestión individual. Esencialmente en todo lo relativo a la generación de residuos (Área 3 del ITMGR), así como al apartado relativo a infraestructuras (Área 4), muy probablemente debido al hecho de estar toda la información centralizada en un único ente, ya sea el consorcio, la mancomunidad, la comarca o el área metropolitana.

Por todo ello, planteamos la siguiente hipótesis:

5. $\mathrm{H}_{5}$ : Existe una relación positiva entre los ayuntamientos que realizan una gestión conjunta de la recogida y/o el tratamiento de los RSU y el nivel de transparencia en la gestión de los residuos municipales.

Con relación a las dos variables económicas seleccionadas, tasa de paro y renta bruta media, creemos que la riqueza del consistorio, medida a través de la renta bruta media de los vecinos puede incidir favorablemente en el nivel de transparencia en la gestión de los residuos municipales, dado que el consistorio a través de una mayor recaudación fiscal, consecuencia de unos mayores niveles de renta, podría destinar una parte de dichos recursos a la publicación de información relacionada con la gestión de los RSU. Si bien es cierto que en la mayoría de las investigaciones sobre la transparencia municipal como las de Frías-Aceituno et al. (2014), Laswad et al. (2005), Albalate (2013), Alcaraz-Quiles (2014), y Navarro et al. (2016), la variable nivel de renta es poco significativa y prácticamente no incide en unos mayores niveles de transparencia.

Por todo ello planteamos la siguiente hipótesis:

6. $\mathrm{H}_{6}$ : Existe una relación positiva entre la renta bruta media per cápita y el nivel de transparencia en la gestión de los residuos municipales.

En lo que respecta a las siete variables presupuestarias seleccionadas, entendemos que los ingresos fiscales tal como demuestran los estudios previos de Atl et al. (2006), Esteller-Moré y Polo (2008) y García et al. (2016), son poco significativos con relación al nivel de transparencia. Basándonos también en las investigaciones de Cárcaba y García (2008), Alcaráz-Quiles (2014), Albalate (2013) y Alcaráz-Quiles et al. 
(2015), entendemos que el nivel de endeudamiento del ayuntamiento no es significativo con relación al nivel de transparencia relacionado con la gestión de los RSU. Esa misma postura la mantenemos también para las variables autonomía financiera e inversiones por habitante.

Con relación a las tasas municipales por recogida y tratamiento de residuos para viviendas particulares, en la muestra seleccionada, hemos observado que 74 ayuntamientos si la cobran, prácticamente el $77 \%$, mientras que, en 22 consistorios, no se cobra o es recaudada por una entidad supramunicipal. Con relación al carácter de la cuota tributaria, el reparto es prácticamente al 50\% (en 37 ayuntamientos es variable y en los otros 37 es fija). Los criterios empleados en la cuota variables son, mayoritariamente la categoría fiscal de la calle, que se aplica en 27 ayuntamientos, seguida del consumo de agua en 7 ayuntamientos, la superficie de la vivienda que la aplican los consistorios de Vitoria y Reus, y por último el número de residentes empleada en el ayuntamiento de Tarrasa. Entendemos, tal como afirman Chamizo-González et al. (2016), que dichos criterios no guardan relación con la generación de los RSU, ni con los costes de tratamiento, y por ende tampoco con el nivel de transparencia, por tanto, dicha variable la consideramos poco significativa con relación a los datos que muestre el ITMGR.

Por último, de las dos variables sobre el gasto presupuestario asociado a la gestión de los RSU, entendemos que el gasto per cápita en la gestión de los residuos municipales, puede tener una relación positiva más significativa que el porcentaje que representa el programa de gastos 162. "Recogida, Gestión y Tratamiento de Residuos" sobre el presupuesto de gastos del ayuntamiento, al estar la primera variable ponderada en función de la población. Si bien, las investigaciones previas de La Porte et al. (2002), y Bastida y Benito (2007) no logran demostrar dicha relación positiva, o incluso determinan una relación negativa entre el incremento del gasto y la transparencia presupuestaria, como en el caso de Caamaño-Alegre et al. (2013). Únicamente la investigación de Guillamón et al. (2011), logra demostrar para los 100 mayores ayuntamientos españoles, una relación positiva entre el gasto per cápita y el ITA 2010, sobre la base de que los gestores públicos incrementan sus niveles de transparencia porque quieren dar a conocer sus políticas de gasto ante los ciudadanos.

Por todo ello, planteamos las siguientes hipótesis:

7. $\mathrm{H}_{7}$ : Existe una relación positiva entre el gasto per cápita en la recogida, gestión y tratamiento de los RSU y el nivel de transparencia en la gestión de los residuos municipales.

El resumen de todas las hipótesis planteadas queda reflejado en el siguiente cuadro.

Cuadro. 5. Tipo de relación entre las variables elegidas y el ITMGR.

\begin{tabular}{|l|c|c|}
\hline \multicolumn{1}{|c|}{ Hipótesis y variables seleccionadas } & Relación (+) & Relación (-) \\
\hline $\mathrm{H}_{1}$. Población & $\mathbf{X}$ & \\
\hline $\mathrm{H}_{2}$. Porcentaje de impropios & $\mathbf{X}$ \\
\hline $\mathrm{H}_{3}$. Recogida separada de los r. orgánicos & $\mathbf{X}$ & \\
\hline $\mathrm{H}_{4}$ Gestión directa & $\mathbf{X}$ & \\
\hline $\mathrm{H}_{5}$ Gestión conjunta & $\mathbf{X}$ & \\
\hline $\mathrm{H}_{6}$. Renta bruta media & $\mathbf{X}$ & \\
\hline $\mathrm{H}_{7}$. Gasto per cápita (programa 162) & & \\
\hline
\end{tabular}

Fuente: Elaboración propia

Se ha utilizado el paquete estadístico Gretl para el contraste de las hipótesis planteadas anteriormente, incluyendo tanto la variable explicada o dependiente (índice de trasparencia de cada ayuntamiento: ITMGR) como todas las variables explicativas o independientes:

Variable dependiente $_{\mathrm{i}}=\Sigma \beta_{\mathrm{j}}$ Variable independiente $_{\mathrm{i}}+\mu_{\mathrm{i}}$ 
El modelo finalmente desarrollado utilizando aquellas variables que han presentado resultados significativos, presenta la siguiente estructura:

ITMGR $_{\mathrm{i}}=\beta_{1} \operatorname{LogRBMED}_{\mathrm{i}}+\beta_{2}$ LogPOB $_{\mathrm{i}}+\beta_{3} \operatorname{LogINGFIS}_{\mathrm{i}}+\beta_{4}$ CONT $_{\mathrm{i}}+\beta_{5}$ PTOGASTOS $_{\mathrm{i}}+$

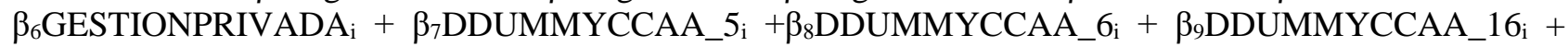
$\beta_{10}$ DDUMMYCCAA_ $18_{\mathrm{i}}+\mu_{\mathrm{i}}$

Como puede apreciarse en la siguiente tabla, los coeficientes $\beta_{\mathrm{j}}$ de la Renta Bruta, la Población, los Ingresos Fiscales, el disponer del Contenedor de recogida de Materia Orgánica, el porcentaje que representa el Programa 162 de Recogida, Gestión y Tratamiento de Residuos sobre el Presupuesto de Gastos, la Gestión Privada y algunas variables dicotómicas autonómicas (DUMMY CCAA 5,6,16 y 18) presentan un p valor muy significativo, al igual que el Test $\mathrm{F}$ de significatividad conjunta de las variables independientes. El coeficiente de determinación $\mathrm{R}^{2}$ del modelo, bondad del ajuste mínimo-cuadrático, presenta un valor cercano al $95 \%$ con las variables seleccionadas.

Tabla. 1. Modelo MCO. Variable dependiente: ITMGR.

Modelo MCO.

Variable dependiente: ITMGR.

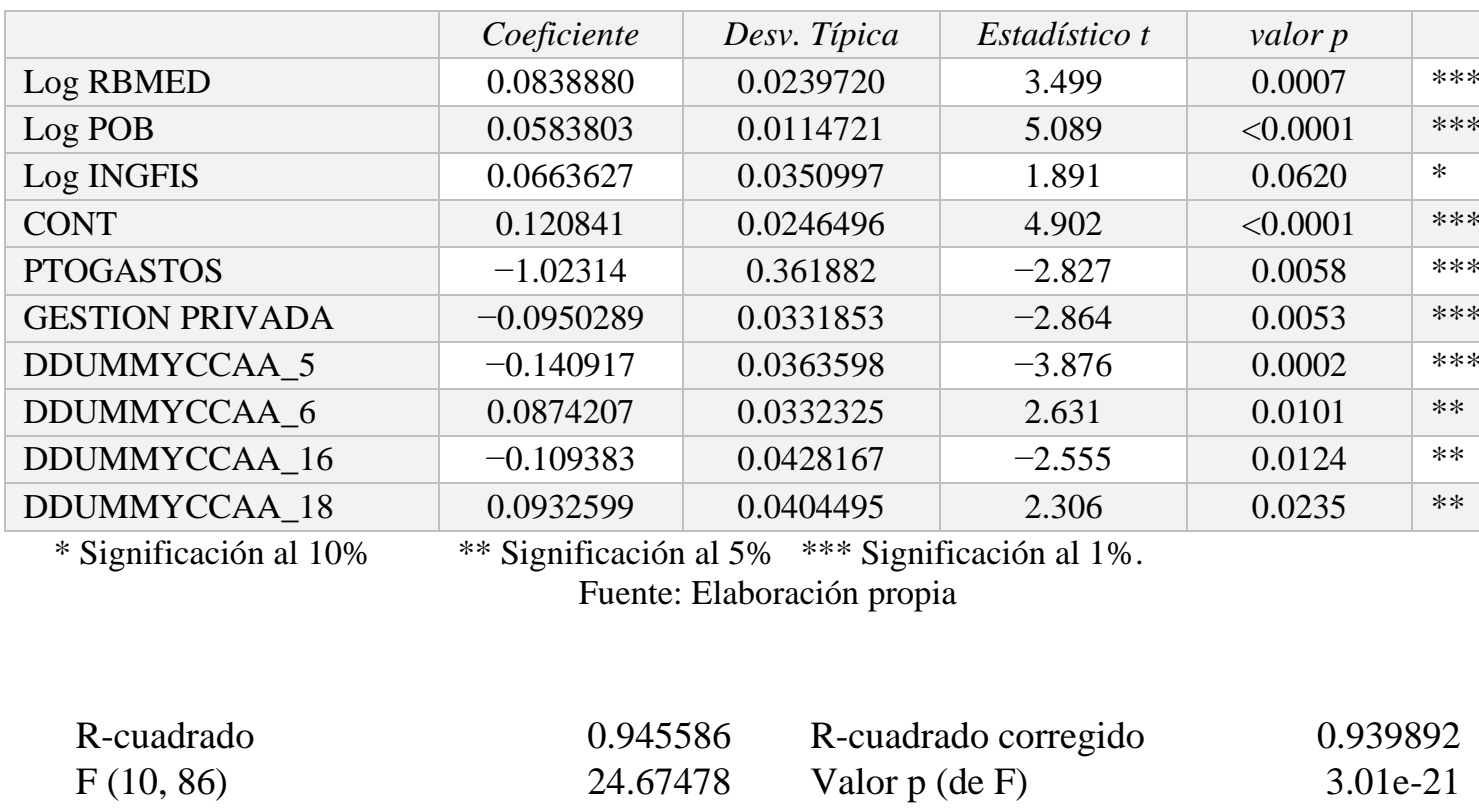

La siguiente tabla muestra los estadísticos más habituales de todas las variables utilizadas en el modelo: 
Tabla. 2. Estadísticos principales.

\begin{tabular}{|c|c|c|c|c|c|}
\hline Variable & Media & Mediana & D. T. & Mín & Máx \\
\hline INDTRAS & 0.426 & 0.391 & 0.162 & 0.0781 & 0.797 \\
\hline POBMIL & 213. & 132. & 369. & 11.3 & $3.18 \mathrm{e}+003$ \\
\hline POB65 & 0.186 & 0.184 & 0.0367 & 0.0984 & 0.265 \\
\hline NIVEDUC & 0.361 & 0.361 & 0.0699 & 0.126 & 0.520 \\
\hline IMPRO & 0.256 & 0.248 & 0.0777 & 0.0950 & 0.493 \\
\hline CAPPROV & 0.542 & 1.00 & 0.501 & 0.000 & 1.00 \\
\hline AYTOTURMIL & 5.31 & 2.01 & 13.4 & 0.0640 & 101. \\
\hline AYTOCOST & 0.368 & 0.000 & 0.485 & 0.000 & 1.00 \\
\hline CONT & 0.323 & 0.000 & 0.470 & 0.000 & 1.00 \\
\hline IDEO & 0.406 & 0.000 & 0.494 & 0.000 & 1.00 \\
\hline IDEOCOIN & 0.604 & 1.00 & 0.492 & 0.000 & 1.00 \\
\hline PARO & 0.178 & 0.166 & 0.0543 & 0.0825 & 0.332 \\
\hline RBMEDMIL & 26.9 & 25.9 & 5.00 & 19.3 & 50.7 \\
\hline DEUHABMIL & 0.593 & 0.401 & 0.690 & 0.000 & 3.73 \\
\hline GASTOHEUROS & 66.8 & 60.9 & 44.7 & 3.89 & 392. \\
\hline PTOGASTOS & 0.0646 & 0.0581 & 0.0320 & 0.00556 & 0.192 \\
\hline TASBASURA & 0.781 & 1.00 & 0.416 & 0.000 & 1.00 \\
\hline INVERHABEUROS & 85.8 & 73.1 & 60.7 & 8.54 & 300. \\
\hline AUTONFINAN & 0.672 & 0.684 & 0.0980 & 0.247 & 0.856 \\
\hline INGFISMIL & 0.671 & 0.625 & 0.225 & 0.407 & 1.69 \\
\hline GESTIONINDIVIDUAL & 0.781 & 1.00 & 0.416 & 0.000 & 1.00 \\
\hline GESTIONCONJUNTA & 0.229 & 0.000 & 0.423 & 0.000 & 1.00 \\
\hline GESTIONPUBLICA & 0.219 & 0.000 & 0.416 & 0.000 & 1.00 \\
\hline GESTIONPRIVADA & 0.781 & 1.00 & 0.416 & 0.000 & 1.00 \\
\hline DDUMMYCCAA_0 & 0.115 & 0.000 & 0.320 & 0.000 & 1.00 \\
\hline DDUMMYCCAA_1 & 0.0417 & 0.000 & 0.201 & 0.000 & 1.00 \\
\hline DDUMMYCCAA_2 & 0.0417 & 0.000 & 0.201 & 0.000 & 1.00 \\
\hline DDUMMYCCAA_3 & 0.0313 & 0.000 & 0.175 & 0.000 & 1.00 \\
\hline DDUMMYCCAA_4 & 0.0417 & 0.000 & 0.201 & 0.000 & 1.00 \\
\hline DDUMMYCCAA_5 & 0.0417 & 0.000 & 0.201 & 0.000 & 1.00 \\
\hline DDUMMYCCAA_6 & 0.0938 & 0.000 & 0.293 & 0.000 & 1.00 \\
\hline DDUMMYCCAA_7 & 0.0521 & 0.000 & 0.223 & 0.000 & 1.00 \\
\hline DDUMMYCCAA_8 & 0.115 & 0.000 & 0.320 & 0.000 & 1.00 \\
\hline DDUMMYCCAA_9 & 0.0417 & 0.000 & 0.201 & 0.000 & 1.00 \\
\hline DDUMMYCCAA_10 & 0.0625 & 0.000 & 0.243 & 0.000 & 1.00 \\
\hline DDUMMYCCAA_11 & 0.104 & 0.000 & 0.307 & 0.000 & 1.00 \\
\hline DDUMMYCCAA_12 & 0.0417 & 0.000 & 0.201 & 0.000 & 1.00 \\
\hline DDUMMYCCAA_13 & 0.0313 & 0.000 & 0.175 & 0.000 & 1.00 \\
\hline DDUMMYCCAA_14 & 0.0417 & 0.000 & 0.201 & 0.000 & 1.00 \\
\hline DDUMMYCCAA_15 & 0.0417 & 0.000 & 0.201 & 0.000 & 1.00 \\
\hline DDUMMYCCAA_16 & 0.0417 & 0.000 & 0.201 & 0.000 & 1.00 \\
\hline DDUMMYCCAA_17 & 0.0104 & 0.000 & 0.102 & 0.000 & 1.00 \\
\hline DDUMMYCCAA_18 & 0.0104 & 0.000 & 0.102 & 0.000 & 1.00 \\
\hline Log POB & 4.85 & 4.88 & 0.938 & 2.43 & 8.07 \\
\hline Log RBMED & 3.28 & 3.25 & 0.158 & 2.96 & 3.93 \\
\hline Log INGFIS & -0.440 & -0.471 & 0.273 & -0.898 & 0.524 \\
\hline
\end{tabular}

Fuente: Elaboración propia

La afirmación de que el modelo no presenta problemas serios de multicolinealidad puede verificarse adicionalmente examinando la tabla de la matriz de correlación de las variables independientes, que se muestra a continuación: 
Tabla. 3. Matriz de coeficientes de correlación de las variables independientes.

\begin{tabular}{|l|c|c|c|c|c|c|c|c|c|c|}
\hline & $\begin{array}{c}\text { Log } \\
\text { RBME } \\
\mathrm{D}\end{array}$ & $\begin{array}{c}\text { Log } \\
\text { POB }\end{array}$ & $\begin{array}{c}\text { Log } \\
\text { INGFIS }\end{array}$ & CONT & $\begin{array}{c}\text { PTO } \\
\text { GASTO } \\
\text { S }\end{array}$ & $\begin{array}{c}\text { GESTION } \\
\text { PRIVAD } \\
\text { A }\end{array}$ & $\begin{array}{c}\text { DDUMM } \\
\text { Y } \\
\text { CCAA_5 }\end{array}$ & $\begin{array}{c}\text { DDUMM } \\
\text { Y } \\
\text { CCAA_6 }\end{array}$ & $\begin{array}{c}\text { DDUMM } \\
\text { CCAA_16 }\end{array}$ & $\begin{array}{c}\text { DDUMMY } \\
\text { CCAA_18 }\end{array}$ \\
\hline $\begin{array}{l}\text { Log } \\
\text { RBMED }\end{array}$ & 1 & 0.2710 & 0.3547 & 0.3704 & -0.50 & 0.0646 & -0.02692 & -0.0973 & -0.0608 & 0.0554 \\
\hline Log POB & 0.3069 & 1 & 0.1758 & 0.2350 & -0.0325 & -0.0006 & -0.0802 & -0.0856 & 0.0946 & -0.0354 \\
\hline Log INGFIS & 0.3547 & 0.0590 & 1 & -0.0577 & 0.1178 & -0.0403 & 0.0386 & 0.0112 & -0.0436 & 0.2603 \\
\hline CONT & 0.3704 & 0.2782 & -0.0577 & 1 & -0.1701 & 0.1499 & -0.0325 & -0.0693 & 0.0790 & -0.0709 \\
\hline $\begin{array}{l}\text { PTO } \\
\text { GASTOS }\end{array}$ & -0.050 & 0.0511 & 0.1178 & -0.1701 & 1 & -0.0984 & 0.0060 & -0.1708 & -0.0021 & -0.1547 \\
\hline $\begin{array}{l}\text { GESTION } \\
\text { PRIVADA }\end{array}$ & -0.0644 & -0.1097 & -0.0403 & 0.1440 & -0.0036 & 1 & 0.1103 & 0.0837 & 0.1103 & 0.0543 \\
\hline $\begin{array}{l}\text { DDUMMY } \\
\text { CCAA_5 }\end{array}$ & -0.0262 & -0.0802 & 0.0386 & -0.0325 & 0.0060 & 0.1103 & 1 & -0.0671 & -0.0435 & -0.0214 \\
\hline $\begin{array}{l}\text { DDUMMY } \\
\text { CCAA_6 }\end{array}$ & -0.0973 & -0.0856 & 0.0112 & -0.0693 & 0.1708 & 0.0837 & -0.0671 & 1 & -0.0671 & -0.0330 \\
\hline $\begin{array}{l}\text { DDUMMY } \\
\text { CCAA_16 }\end{array}$ & -0.0608 & 0.0946 & -0.0436 & 0.079 & -0.0021 & 0.1103 & -0.0435 & -0.0671 & 1 & -0.0214 \\
\hline $\begin{array}{l}\text { DDUMMY } \\
\text { CCAA_18 }\end{array}$ & 0.0554 & -0.0354 & 0.2603 & -0.0709 & -0.1547 & 0.0543 & -0.0214 & -0.0330 & -0.0105 & 1 \\
\hline
\end{tabular}

Fuente: Elaboración propia

\section{Resultados del análisis}

Los resultados obtenidos nos indican con relación a las tres primeras hipótesis planteadas que hacen referencia a las variables socio-demográficas, una relación positiva muy significativa $(p<0.0001)$ entre el nivel de transparencia en la gestión de residuos municipales y el número de habitantes del municipio, en línea con anteriores investigaciones similares como Serrano et al. (2008), Cárcaba y García (2008), Martín y García (2011), Alonso y García-García (2014), Frías-Aceituno et al. (2014); Alcaráz-Quiles (2014), TejedoRomero y Ferraz (2015) y (2018) y Navarro et al. (2016). De la misma manera existe una relación positiva significativa $(p<0.0001)$, entre los ayuntamientos que tienen implantada una recogida separada de la materia orgánica y los valores del ITMGR, por el contrario, dicha circunstancia no se produce con relación a la variable porcentaje de impropios depositados en el contenedor de envases y, por tanto, la $\mathrm{H}_{2}$ no está soportada y debe rechazarse.

Con relación a las variables de gestión $\left(\mathrm{H}_{4} \mathrm{y} \mathrm{H}_{5}\right)$, los datos indican que no se produce una relación positiva y significativa entre el nivel de transparencia y los consistorios que realizan una gestión directa o aquellos que realizan una gestión conjunta de la recogida y/o tratamiento de los RSU, por lo que ambas hipótesis deben rechazarse.

Por último, con relación a las variables económico-presupuestarias $\left(\mathrm{H}_{6} \mathrm{y} \mathrm{H}_{7}\right)$, los resultados de nuestra investigación muestran una relación positiva muy significativa $(\mathrm{p}=0.0007)$, entre la renta bruta media y el nivel de transparencia en la gestión de los residuos municipales. Por tanto, la $\mathrm{H}_{6}$ debe aceptarse, en línea con las conclusiones del estudio de Serrano et al. (2008). Por el contrario, la variable gasto per cápita en la recogida, gestión y tratamiento de los RSU no es significativa, por lo que la $\mathrm{H}_{7}$ no está soportada y debe rechazarse.

El resumen de la contrastación de las hipótesis planteadas se puede apreciar en el siguiente cuadro: 
Cuadro. 6. Contrastación de hipótesis.

\begin{tabular}{|l|c|c|c|}
\hline \multicolumn{1}{|c|}{$\begin{array}{c}\text { Hipótesis y variables } \\
\text { seleccionadas }\end{array}$} & Relación (+) & Relación (-) & $\begin{array}{c}\text { Contrastación de } \\
\text { hipótesis }\end{array}$ \\
\hline $\mathrm{H}_{1}$. Población & $\mathbf{X}$ & $\mathbf{X}$ & Aceptada \\
\hline $\begin{array}{l}\mathrm{H}_{2} \text {. Porcentaje de } \\
\text { impropios }\end{array}$ & $\mathbf{X}$ & & Aceptada \\
\hline $\begin{array}{l}\mathrm{H}_{3} \text {. Recogida separada de } \\
\text { los residuos orgánicos }\end{array}$ & $\mathbf{X}$ & & Rechazada \\
\hline $\mathrm{H}_{4}$ Gestión directa & $\mathbf{X}$ & & Rechazada \\
\hline $\mathrm{H}_{5}$ Gestión conjunta & $\mathbf{X}$ & & Aceptada \\
\hline $\mathrm{H}_{6 .}$ Renta bruta media & $\mathbf{X}$ & & Rechazada \\
\hline $\begin{array}{l}\mathrm{H}_{7} \text {. Gasto per cápita } \\
\text { (programa 162) }\end{array}$ & & & \\
\hline
\end{tabular}

Fuente: Elaboración propia

Además del análisis sobre el cumplimiento o no de nuestras hipótesis, los resultados indican una relación negativa significativa $(\mathrm{p}=0.0058)$ entre el porcentaje que representa el programa 162.Recogida, Gestión y Tratamiento de Residuos" sobre el presupuesto de gastos del ayuntamiento, que se alinearía con los resultados obtenidos por Caamaño-Alegre et al. (2013) sobre la transparencia presupuestaria. De la misma manera se aprecia una relación negativa significativa $(\mathrm{P}=0.0053)$ con la variable gestión indirecta, es decir, los ayuntamientos que realizan una recogida de los RSU a través de una empresa privada presentan un ITMGR más bajo.

Igualmente, los resultados indican una relación positiva algo significativa $(\mathrm{P}=0.0620)$ entre el nivel de transparencia y aquellos ayuntamientos con mayores ingresos fiscales per cápita, en cierta manera, consecuencia de nuestra hipótesis 6 , los ayuntamientos con mayores niveles de renta presentan índices más elevados de transparencia.

Para finalizar, en relación con las variables dicotómicas el modelo no presenta intercepto, con lo que se han tenido en cuenta las 19 variables categóricas relativas a cada una de las Comunidades Autonómicas además de Ceuta y Melilla. Los coeficientes representan el promedio, o media, de la variación del ITMGR en cada uno de los municipios considerados por el hecho de pertenecer a una determinada Comunidad Autónoma. Según nuestro estudio, solamente cuatro de ellas, Cantabria (-), Castilla y León (+), la Comunidad Valenciana (-) y la Ciudad Autónoma de Melilla (+), presentan parámetros significativos, tal como se puede apreciar en la siguiente tabla.

Tabla 4. Variables dicotómicas. CCAA.

Modelo MCO

Variable dependiente: ITMGR

\begin{tabular}{|l|c|c|c|c|c|}
\hline & Coeficiente & Desv. Típica & Estadístico $t$ & valor $p$ \\
\hline $\begin{array}{l}\text { DDUMMYCCAA_5 } \\
\text { Cantabria }\end{array}$ & -0.140917 & 0.0363598 & -3.876 & 0.0002 & $* * *$ \\
\hline $\begin{array}{l}\text { DDUMMYCCAA_6 } \\
\text { Castilla y León }\end{array}$ & 0.0874207 & 0.0332325 & 2.631 & 0.0101 & $* *$ \\
\hline $\begin{array}{l}\text { DDUMMYCCAA_16 } \\
\text { C. Valenciana }\end{array}$ & -0.109383 & 0.0428167 & -2.555 & 0.0124 & $* *$ \\
\hline $\begin{array}{l}\text { DDUMMYCCAA_18 } \\
\text { C. A. de Melilla }\end{array}$ & 0.0932599 & 0.0404495 & 2.306 & 0.0235 & $* *$ \\
\hline
\end{tabular}

Fuente: Elaboración propia. 


\section{Conclusiones}

Una vez finalizado el estudio empírico y contrastadas nuestras hipótesis podemos concluir que únicamente se aceptan tres de las siete planteadas. Las variables independientes porcentaje de impropios depositados en el contenedor de envases $\left(\mathrm{H}_{2}\right)$, la gestión directa de la recogida de los $\mathrm{RSU}\left(\mathrm{H}_{4}\right)$, la gestión conjunta (a través de consorcios, mancomunidades u áreas metropolitanas) de la recogida y tratamiento de los $\mathrm{RSU}\left(\mathrm{H}_{5}\right)$ y el gasto per cápita (programa 162) en la recogida, gestión y tratamiento de los $\mathrm{RSU}\left(\mathrm{H}_{7}\right)$, no presentan ninguna de ellas una relación significativa con el nivel de transparencia medido a través del ITMGR.

Los resultados confirman que los ayuntamientos con mayor nivel de transparencia en la gestión de los RSU son aquellos que presentan una mayor población $\left(\mathrm{H}_{1}\right)$, en la línea con otras investigaciones [Serrano et al. (2008), Cárcaba y García (2008), Martín y García (2011), Alonso y García-García (2014), Frías-Aceituno et al. (2014); Alcaráz-Quiles (2014), Tejedo-Romero y Ferraz (2015) y (2018) y Navarro et al. (2016)], mayores niveles de renta bruta media $\left(\mathrm{H}_{6}\right)$ [Serrano et al. (2008)] y realizan una recogida separada de los residuos orgánicos $\left(\mathrm{H}_{3}\right)$, presentando las tres variables una relación positiva muy significativa. Por el contrario, aquellos ayuntamientos con una gestión indirecta en la recogida de los RSU y con un mayor peso relativo del programa 162 (Recogida, gestión y tratamiento de residuos), presentan unos menores niveles de transparencia, este segundo aspecto, en consonancia con el estudio de Caamaño-Alegre et al. (2013).

Aunque los problemas ambientales exigen soluciones globales bajo la responsabilidad de los gobiernos nacionales, consideramos que los ayuntamientos desempeñan un papel fundamental en el cambio del tradicional modelo productivo lineal (producir-consumir-tirar) al que promulga la nueva economía circular, basado en reincorporar los residuos al proceso productivo como materias primas, fomentando el reciclaje, la recuperación y la reutilización.

Entendemos que cualquier política pública que no cuente con el apoyo de la ciudadanía puede estar condenada al fracaso, en concreto, en la generación y tratamiento de residuos, consideramos fundamental la implicación de todos los actores, el triángulo formado por todas las AAPP y en particular por las CCLL, el sector privado y los ciudadanos. Para lograr la implicación de estos últimos, consideramos que la misma no se alcanzará plenamente a menos que estén bien informados, a través de campañas de concienciación y protección del medio ambiente. Por tanto, la transparencia y la participación ciudadana deberían tener cada vez más fuerza en la estrategia de gobierno de las CCLL.

Otra serie de medidas complementarias como por ejemplo que las tasas municipales reflejen el verdadero coste del servicio y la implantación de un sistema de pago por generación dado que las cuotas fijas discriminan a aquellos vecinos que generan menos residuos domésticos y los parámetros ligados a las cuotas variables (valor catastral o consumo de agua) no están relacionados con la generación de residuos. Incrementar las bonificaciones y exenciones fiscales que premien determinadas conductas responsables con la gestión de los RSU, podrían también contribuir a cambiar determinados malos hábitos relacionados con el reciclaje y la separación en origen de las distintas fracciones de residuos, para en definitiva lograr un crecimiento sostenible respetando y cuidando nuestro medio ambiente.

Para finalizar nuestra investigación consideramos oportuno indicar que la complejidad y el tiempo empleado en la búsqueda de información han imposibilitado el análisis de un mayor número de consistorios, quedando la muestra definitiva compuesta por 96 ayuntamientos. De la misma manera, por cuestiones obvias de tiempo, no se ha podido llevar a cabo un análisis histórico que implicaría la realización de consultas y búsqueda de datos en varios años. Por tanto, las futuras líneas de investigación deberían ir encaminadas a:

- Realizar un estudio comparativo del ITMGR a una muestra más amplia de años y de CCLL con distintos tamaños poblacionales, aplicando criterios de segmentación generalmente admitidos, para diferenciar entre grandes, medianos y pequeños.

- Ampliar el alcance del estudio econométrico, completándolo con el análisis de otras posibles variables que pudieran ejercer una cierta influencia en la publicación de información relacionada con la gestión de los RSU.

Con el objetivo de mejorar la transparencia municipal, sería útil el estudio de la estructura, contenido y formato de una memoria anual de gestión y sostenibilidad estandarizada, con información relevante sobre la gestión de los RSU.

\section{Referencias bibliográficas}

Agencia de Protección Ambiental de los Estados Unidos. Waste and Climate Change - Global Trends and Strategy Framework (2010). http://wedocs.unep.org/handle/20.500.11822/8648. 
Albalate, D. D. S. (2013) The institutional, economic and social determinants of local government transparency. Journal of Economic Policy Reform, 16(1), pp. 90-107. https://doi.org/10.1080/17487870.2012.759422.

Alcaide Muñoz, L., \& Rodríguez Bolivar, M.P. (2015) Determining factors of transparency and accountability in local governments: A meta-analytic study. Lex Localis, 13(2), 129. https://doi.org/10.4335/13.2.129-160(2015).

Alcaraz-Quiles, F. J. (2014) Análisis de las prácticas de responsabilidad social en gobiernos locales: Un estudio empírico. Tesis Doctoral. Facultad de CCEE. Universidad de Granada. http://digibug.ugr.es/bitstream/handle/10481/31729/23009883.pdf?sequence=1\&isAllowed=y.

Alcaraz-Quiles, F. J., Navarro-Galera, A., \& Ortiz-Rodríguez, D. (2015) Factors Determining Online Sustainability Reporting by Local Governments. International Review of Administrative Sciences, 81(1), pp. 79-109. https://doi.org/10.1177\%2F0020852314541564.

Alonso, M. L. M., \& García-García, J. G. (2014) Evaluación de la transparencia municipal en el Principado de Asturias. Auditoría Pública. (64), pp. 75-86. https://asocex.es/wp-content/uploads/PDF/Pag\%207586\%20\%20n\%C2\%BA\%2064.pdf.

Alt, J. E., Lassen, D. D., \& Rose, S. (2006) The causes of fiscal transparency: Evidence from the US States. IMF Staff Papers, 53(1), pp. 30-57.

Banco Mundial: What a Waste: A Global Review of Solid Waste Management (2012) http://documentos.bancomundial.org/curated/es/302341468126264791/What-a-waste-a-global-review-of-solidwaste-management.

Caamaño-Alegre, J., Lago-Peñas, S., Reyes-Santias, F., \& Santiago-Boubeta, A. (2013) Budget transparency in local governments: An empirical analysis. Local Government Studies, 39(2), pp. 182-207. https://www.tandfonline.com/doi/abs/10.1080/03003930.2012.693075.

Cañizares Espada, M. (2015) Análisis de la transparencia en la información y gestión telemática de los servicios sociales españoles a nivel municipal. Tesis Doctoral. UCM. Madrid. https://eprints.ucm.es/id/eprint/40729/1/T38177.pdf.

Cárcaba, A. G., \& García, J. G. (2008) Determinantes de la divulgación de información contable a través de internet por parte de los gobiernos locales. Revista Española de Financiación y Contabilidad, 37(137), pp. 63-84. http://aeca.es/old/refc 1972-2013/2008/137-4.pdf.

Chamizo-González, J., Cano-Montero, E. I., \& Muñoz-Colomina, C. I. (2016) Municipal solid waste management services and its funding in Spain. Resources, Conservation and Recycling, 107, pp. 65-72. https://doi.org/10.1016/j.resconrec.2015.12.006.

Esteller-Moré, a., \& Polo Otero, J. (2012) Fiscal transparency: (Why) does your local government respond? Public Management Review, 14(8), pp. 1153-1173. https://doi.org/10.1080/14719037.2012.657839.

Eurobarómetro 2020: https://www.aragon.es/documents/20127/10701991/encuesta_del_Eurobar_metro_La_protecci_n_del_medio_ambi ente.pdf/c4fed4ed-c0b0-27f9-17f7-4a25ea882201?t=1583236053262.

Frías-Aceituno, J. V., García-Sánchez, I. M., \& Rodríguez-Domínguez, L. (2014) Electronic administration styles and their determinants. evidence from spanish local governments. Transylvanian Review of Administrative Sciences, 10(41), pp. 90-108. https://www.rtsa.ro/tras/index.php/tras/article/view/158.

Gallego-Álvarez, I., \& Quina-Custodio, I. A. (2016) Disclosure of corporate social responsibility information and explanatory factors. Online Information Review. https://doi.org/10.1108/OIR-04-2015-0116.

García-Sánchez, I. M., Cuadrado-Ballesteros, B., \& Frias-Aceituno, J. V. (2016) Impact of the institutional macro context on the voluntary disclosure of CSR information. Long Range Planning, 49(1), pp. 15-35. https://doi.org/10.1016/j.lrp.2015.02.004.

García, J. G., Alonso, M. I. M., \& Alonso, M. L. M. (2016) Determinantes de la transparencia en municipios de mediano y pequeño tamaño. Auditoría Pública, (67), pp. 51-60. http://asocex.es/wp-content/uploads/PDF/Auditoria\%20Publica\%2067\%20pag\%2051-60.pdf.

Guillamón, M., Bastida, F., \& Benito, B. (2011) The determinants of local government's financial transparency. Local Government Studies, 37(4), pp. 391-406. https://doi.org/10.1080/03003930.2011.588704.

La Porte, T. M., Demchak, C. C., \& De Jong, M. (2002) Democracy and bureaucracy in the age of the web: Empirical findings and theoretical speculations. Administration \& Society, 34(4), pp. 411-446. https://doi.org/10.1177\%2F0095399702034004004.

Laswad, F., Fisher, R., \& Oyelere, P. (2005) Determinants of voluntary internet financial reporting by local government authorities. Journal of Accounting and Public Policy, 24(2), pp. $101-121$. https://econpapers.repec.org/scripts/redir.pf?u=http\%3A\%2F\%2Fwww.sciencedirect.com\%2Fscience\%2Farticle $\% 2$ Fpii\%2FS0278-4254\%2804\%2900097-3;h=repec:eee:jappol:v:24:y:2005:i:2:p:101-121.

Lizcano Álvarez, J. (2009) El índice de transparencia de los ayuntamientos: Objetivos y resultados de una experiencia reciente. Análisis Local, (86), pp. 44-56.

Lizcano Álvarez, J. (2013) Transparencia. EUNOMÍA. Revista en Cultura de la Legalidad, pp. 160-166.

Mauro, P. (1995) Corruption and growth. The Quarterly Journal of Economics, Vol 110. $\mathrm{n}^{\circ}$ 3, pp. 681-712. https://www.jstor.org/stable/pdf/2946696.pdf.

Martín, R. M., \& García, F. M. (2011) La influencia de factores institucionales en la transparencia de los ayuntamientos. AECA: Revista de la Asociación Española de Contabilidad y Administración de Empresas, (94), pp. 7-11. http://www.aeca1.org/revistaeca/revista94/94.pdf. 
Naciones Unidas: Conferencia de las Naciones Unidas sobre el Medio Ambiente. Estocolmo (1972) https://www.un.org/spanish/conferences/wssd/unced.html.

Naciones Unidas: Conferencia de las Naciones Unidas sobre el Medio Ambiente y el Desarrollo. Rio de Janeiro (1992) https://www.un.org/spanish/conferences/wssd/unced.html.

Naciones Unidas: Cumbre de las Naciones Unidas sobre el Desarrollo Sostenible. Nueva York. (2015) Transformando nuestro Mundo: la Agenda de Desarrollo Sostenible de 2030.

Naciones Unidas: Organización de las Naciones Unidas para la Alimentación y la Agricultura (FAO). (2015) http://www.fao.org/platform-food-loss-waste/background/es/.

Naciones Unidas: Informe 2017. https://www.unenvironment.org/news-and-stories/story/price-their-heads-how-bottledeposits-help-beat-plastic-pollution.

Naciones Unidas: Asamblea sobre el medioambiente (2017) Nairobi. https://www.unep.org/environmentassembly/.

Naciones Unidas: Informe del Departamento Asuntos Económicos y Sociales (2018) https://www.un.org/development/desa/es/news/population/2018-world-urbanization-prospects.html.

Navarro Heras, E., Mora Agudo, L., \& Delgado Jalón, M. L. (2016) Analyzing the transparency traditional variables within the spanish municipalities. Transylvanian Review of Administrative Sciences, 12(47), pp. 129-145. https://rtsa.ro/tras/index.php/tras/article/view/476/465.

Nevado-Gil, M. T., Gallardo-Vázquez, D., \& Sánchez Hernández, M. I. (2016) Análisis del grado de divulgación de información sobre responsabilidad social en las webs de los principales municipios extremeños. Auditoría Pública, (67), pp. 77-92.

Nevado-Gil, M. T., \& Gallardo-Vázquez, D. (2016) Información sobre responsabilidad social contenida en las páginas webs de los ayuntamientos. Estudio en la región del Alentejo. Revista Española de Documentación Científica, 39(4), 150. http://redc.revistas.csic.es/index.php/redc/article/view/954/1427.

Rodríguez-Martín, A., Palomo-Zurdo, R. \& González-Sánchez, F. (2020) Transparencia y economía circular: análisis y valoración de la gestión municipal de los residuos sólidos urbanos, CIRIEC-España, Revista de Economía Pública, Social y Cooperativa, No 99, pp. 233-272. DOI:107203/CIRIEC-E.99.16011. http://ciriec-revistaeconomia.es/wp-content/uploads/CIRIEC_9909_Rodriguez_et_al.pdf.

Rodríguez-Martín, A. (2020) Análisis y valoración de la transparencia en los municipios españoles en la gestión de los residuos sólidos urbanos. Tesis Doctoral. Facultad de CCEE. Universidad CEU-San Pablo. Madrid. https://repositorioinstitucional.ceu.es/handle/10637/1281.

Ruiz-Lozano, M., Navarro-Galera, A., Tirado-Valencia, P., \& De los Ríos-Berjillos, A. (2019) Can the cultural environment affect governmental transparency on sustainability? Useful measures for policy makers and practitioners. Local Government Studies, 45(4), pp. 481-503. https://doi.org/10.1080/03003930.2018.1560271.

Tejedo-Romero, F., \& Ferraz Esteves-Araujo, J. F. (2015) Determinants of local governments'transparency in times of crisis: Evidence from municipality-level panel data. Administration and Society. pp. 527-554. https://doi.org/10.1177\%2F0095399715607288.

Tejedo-Romero, F., \& Ferraz Esteves-Araujo, J. F. (2018) Transparencia en los municipios españoles: Determinantes de la divulgación de información. Convergencia, 25(78), pp. 153-174. http://www.scielo.org.mx/scielo.php?pid=S1405-14352018000300153\&script=sci_arttext\&tlng=en.

Unión Europea: Comunicación de la Comisión. "Una Estrategia para un crecimiento inteligente, sostenible e integrador”. COM (2010) 2020 Final. Bruselas 03.03.2010.

Unión Europea: Comunicación de la Comisión al Parlamento Europeo, al Consejo, al Comité Económico y Social Europeo y al Comité de las Regiones. "El Pacto Verde Europeo”. COM/2019/640 final. Bruselas 11.12.2019.

Vila i Vila, J. (2013) Determinantes de la transparencia contable en los municipios. XX Encuentro de Economía Pública, 2013. Sevilla. https://idus.us.es/xmlui/handle/11441/30293. 